\title{
Biological Characteristics of Captive Chinese Wuzhishan Minipigs (Sus scrofa)
}

\author{
Fangui Min, ${ }^{1}$ Jinchun Pan, ${ }^{1}$ Xilong Wang, ${ }^{1}$ Rui'ai Chen, ${ }^{2}$ Fengguo Wang, \\ Shuming Luo, ${ }^{2}$ and Jiancong $\mathrm{Ye}^{2}$ \\ ${ }^{1}$ Guangdong Provincial Key Laboratory of Laboratory Animals, Guangdong Laboratory Animals Monitoring Institute, \\ Guangzhou 510663, China \\ ${ }^{2}$ Guangdong Dahuanong Animal Health Products Stock Co., Ltd., Xinxing 527439, China
}

Correspondence should be addressed to Xilong Wang; wangxilonggd@163.com

Received 17 April 2014; Revised 10 June 2014; Accepted 12 June 2014; Published 20 August 2014

Academic Editor: Gregory Ladics

Copyright (C) 2014 Fangui Min et al. This is an open access article distributed under the Creative Commons Attribution License, which permits unrestricted use, distribution, and reproduction in any medium, provided the original work is properly cited.

\begin{abstract}
In order to meet the demands of experimental minipigs for biomedical researches, we have aimed at cultivating grazing Chinese Wuzhishan (WZS) minipigs and trying to make them useful and affordable since the 1990s. After more than ten years of captive cultivation following sound management practices and a rigorous selection program for fertility and litter size, we established an outbred WZS minipigs colony with a core group (14 males and 30 females) and an expanding group (20 males and 40 females). In 2010-2013 periods, extensive background data of this colony were recorded and analyzed. This paper was written to provide pertinent information about outbred WZS minipigs for producers, users, and others concerned with WZS minipigs. It contains physical characteristics, growth performance, productive performance, hematology and blood biochemistry, microsatellite analysis, organ coefficients, and carcass properties. Results show that WZS minipigs have characteristics of small body size, slow growth rate, long life cycle, high reproductive rate, and maintaining original genetic diversity. All data present that outbred WZS minipigs are suitable laboratory animal and model animal.
\end{abstract}

\section{Introduction}

Minipigs, or sometimes potbellied pigs, are strains of domestic pigs that are markedly smaller than farmyard varieties. For their low economic traits, the selection and cultivation of minipigs were far behind domestic farm pigs. Because of anatomical and functional similarities to humans or because of availability of disease models, pigs begin to be used as research models in the field of skin, cardiovascular system, urinary system, and metabolic syndrome [1-3], while the minipigs show a significant advantage over the domestic farm pigs for the reduced size which reduces the compound needs consequential prohibitive costs for the experiments and makes animals handling easier.

The cultivation of miniature pigs began in the 1940s, and more than 10 strains had been used in biomedical researches till the 1980s [4]. In Europe, the Göttingen minipig is the most popular breed used by pharmaceutical companies and contract research organizations. In the USA, strains of Yucatan mini- and micropigs, Sinclair minipigs, Minnesota Hormel minipigs, and Hanford minipigs are widely used today. Though these minipig strains are known as multispecies hybrid bred, their background information is clear and their hereditary stabilities are satisfied. China has rich resources of minipigs such as Chinese Wuzhishan (WZS) minipigs (Sus scrofa), Guizhou minipigs, Bama minipigs, and Tibet minipigs, but the laboratory animal work is far behind the developed countries. Compared with the strains used in developed countries, the Chinese origin minipigs are formed naturally with high genetic homozygosity and stable phenotype [5], indicating that Chinese origin minipigs are more ideal as laboratory animals for biomedical researches.

WZS minipig is a special pig in China initially grazing in isolated tropical areas in Hainan. It was firstly found and preserved in the 1980s; after that, the laboratory WZS minipigs began to be cultivated [6] and used in biomedical 
TABLE 1: Microsatellite loci and grouping in multi-PCR.

\begin{tabular}{lccc}
\hline Group & & Fluorescent labeling & TET \\
\hline 1 & FAM & HEX & $S W R 925$, SW1118, S0018 \\
2 & $S W 255$ & $S W 986$, SW2519 & $S W 71, S W 1035$ \\
3 & $S W 1305, S W 936$ & $S W 1202, S W 1408$ & $S W 2141, S W 1129$ \\
4 & $S W 511, S W 790$ & $S W 520, S W 2459$ & $S W 2001$ \\
5 & $S W 943, S W 65$ & $S W 486$ & $S W 2415, S W 1553$ \\
\hline
\end{tabular}

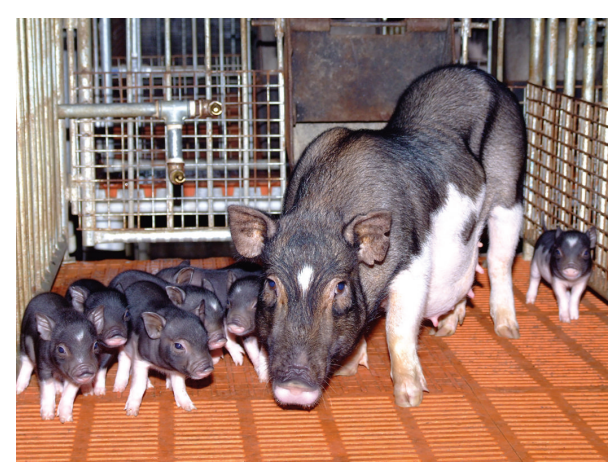

FIGURE 1: Morphological appearance of outbred WZS minipig.

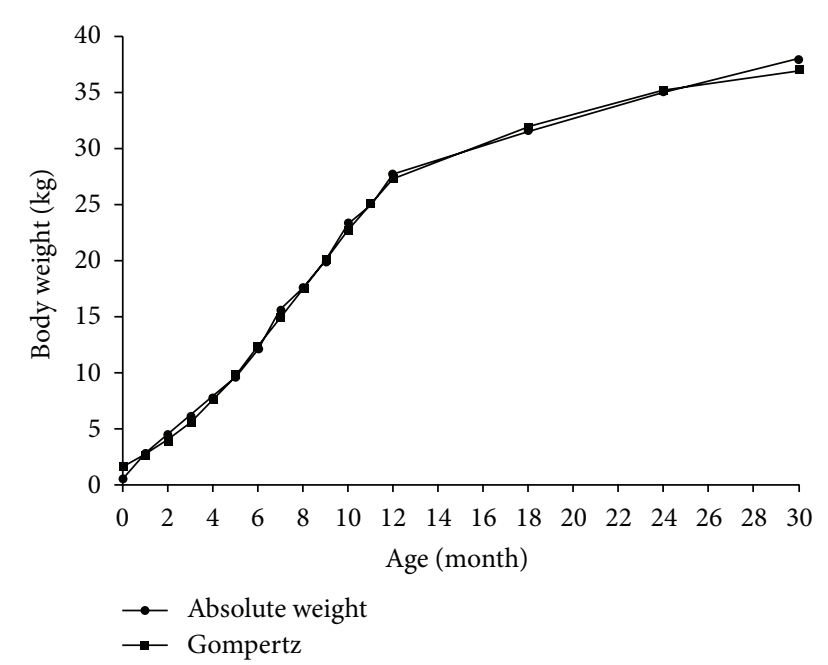

FIGURE 2: Growth curve for body weights of outbred WZS minipigs.

researches $[7,8]$. Nowadays, one WZS minipigs colony for 20 generations of inbreeding has been established with a high inbreeding coefficient (more than 0.965) $[9,10]$. Here we will introduce the outbred WZS minipigs that have been cultivated since the 1990s. After more than ten years of phenotypic selection, downsizing cultivation, and microbiological standardization, we established an outbred WZS minipigs colony and highlighted its background data for its usefulness in modern laboratory animal science, especially for being suitable for long-term studies in which domestic swine breeds become too large.

\section{Material and Methods}

2.1. Experimental Animals. An outbred WZS minipigs colony with a core group (14 males and 30 females) and an expanding group (20 males and 40 females) was set as the objective. All data were collected from them and their offspring in 20102013 periods. The administrative license number is SCXK (Yue)2008-0022.

Animals were bred in closed shelter with cooling water curtains and air supply fans in summer and infrared thermal equipment in winter. Environmental temperatures were normally kept in $18-29^{\circ} \mathrm{C}$ and air exchanges were maintained at about 10 times per hour.

2.2. Clinical Observation. Animals were observed by animal care technicians daily and veterinarian biweekly. All clinical signs were recorded daily and verified by veterinarian periodically.

2.3. Determination of Body Weight and Body Measurement. Body weight (BW) and body measurements were determined monthly up to 12 months and then at the interval of 6 months for BW. BW was taken by weighbridge and body measurements were made using the tailor's tape measure.

Height-at-withers (HAW) was measured as the straightline distance from the withers to the base of the foot in a normal upright manner. Body length (BL) was measured as the distance from scapula to tail. Heart girth (HG), heart depth (HD), and heart breadth (HB) represented the circumference, straight-line distance, and horizontal distance of the chest posterior to the scapula, respectively. Abdomen girth $(A G)$ showed the circumference of abdomen. Shank girth (SG) showed the circumference of the lower parts of the foreleg. Buttock-knee length (BKL) was measured from the most posterior point on either buttock to the anterior point of the knee. Buttocks breadth (BB) was measured as the horizontal distance between buttocks. Head length (HL) was measured from the distalmost dorsal point of the rhinarial pad to parietal. Forehead breadth (FB) was measured as the distance between the eyes. Jaw width (JW) was the distance between two mandibular angles. Caudal length (CL) was the distance from tail root to tail tip. Caudal girth (CG) was the circumference of tail root.

2.4. Measures of Reproductive Performance. The reproductive performances of the colony were monitored continuously for at least 3 birth frequencies according to Records for 


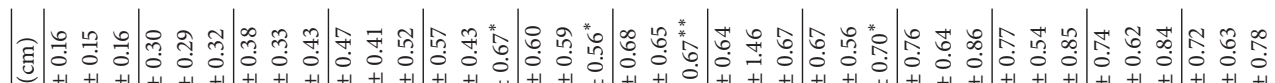

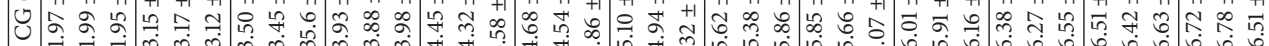

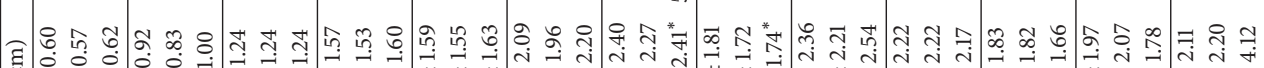

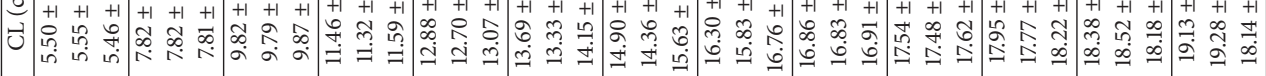

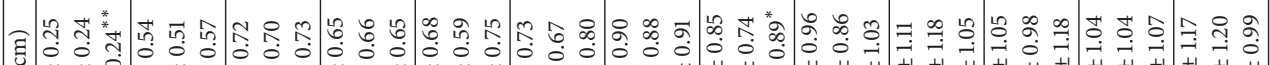

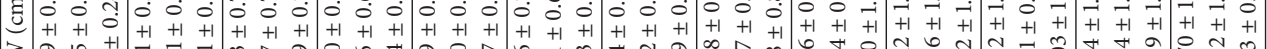

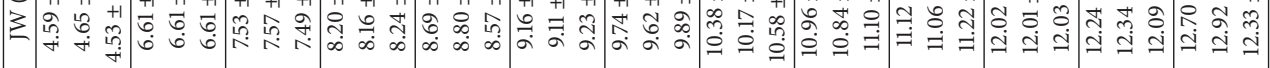

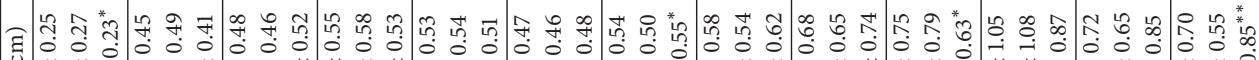

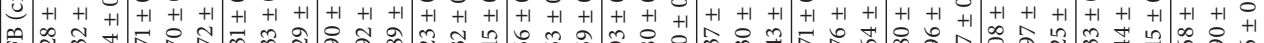

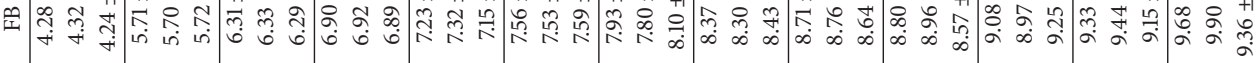

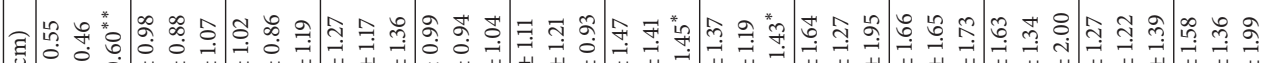

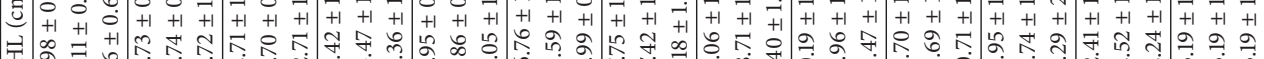

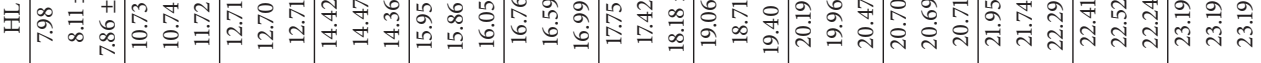

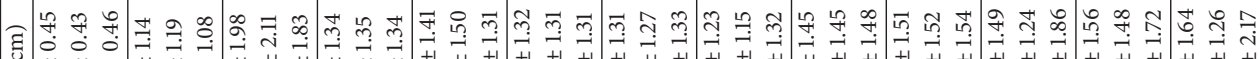

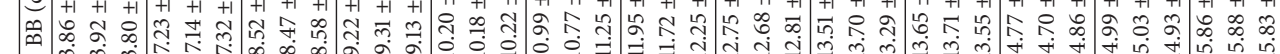

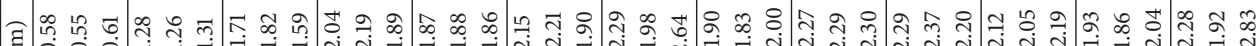

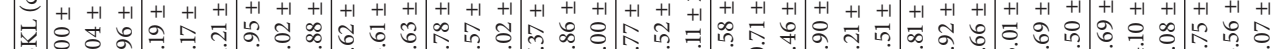

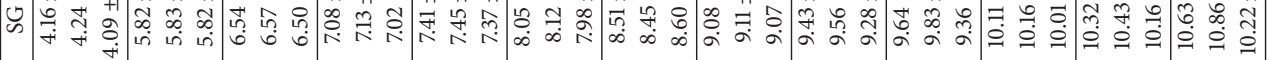

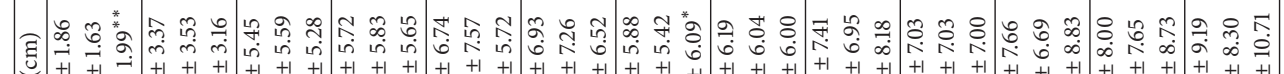

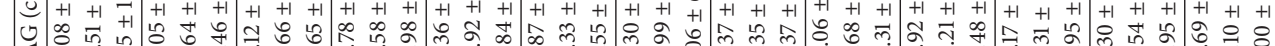

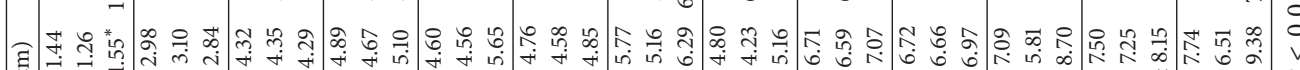

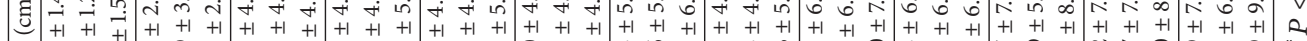

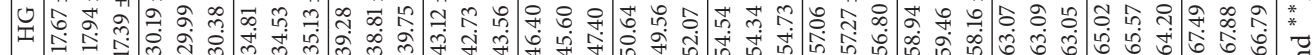

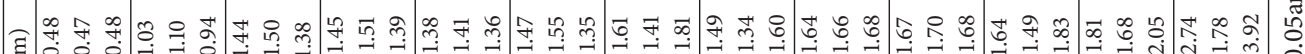

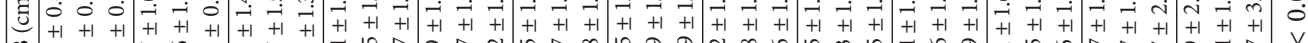

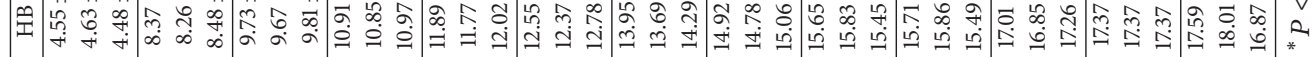

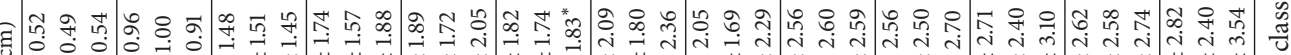

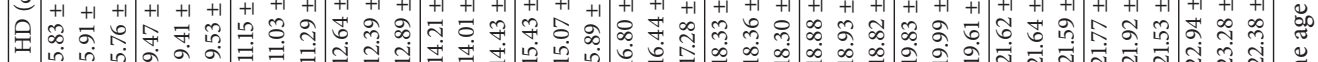

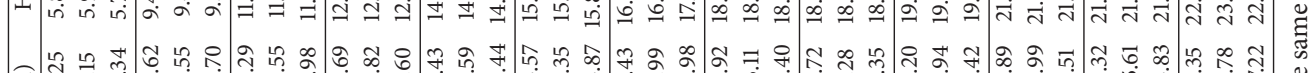

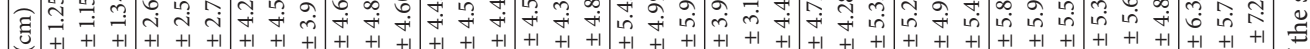

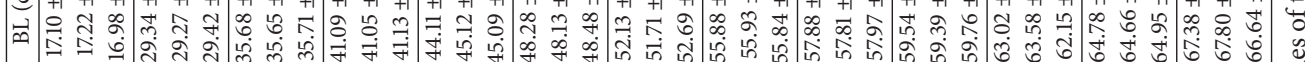
年

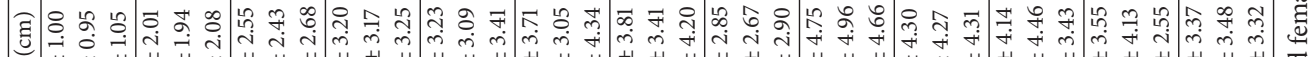

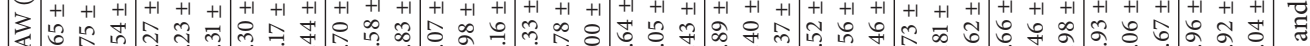

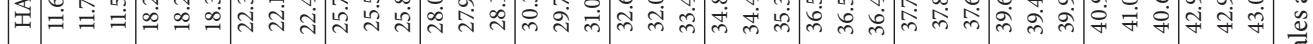

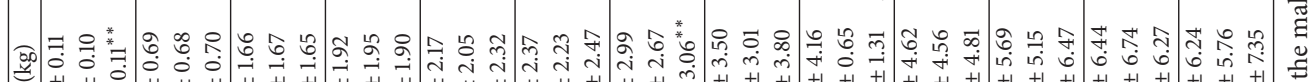

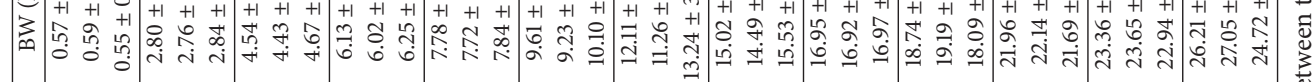

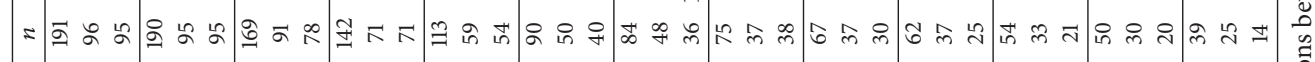

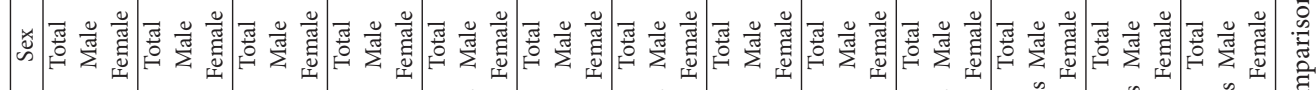

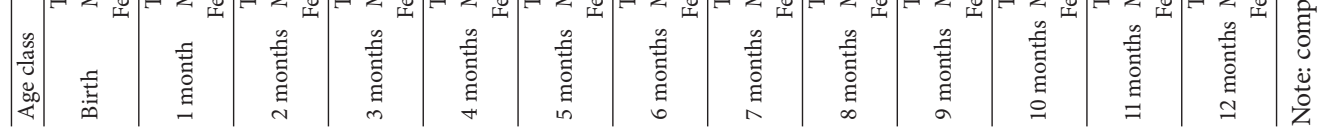


TABLE 3: Parameters of reproductive behavior of outbred WZS minipigs.

\begin{tabular}{lcccc}
\hline$n$ & Puberty $(\mathrm{d})$ & Estrus cycle $(\mathrm{d})$ & Behavioral estrus $(\mathrm{d})$ & Gestation $(\mathrm{d})$ \\
\hline 45 & $93.65 \pm 3.50$ & $21.16 \pm 0.75$ & $4.18 \pm 0.31$ & $113.0 \pm 2.33$ \\
\hline
\end{tabular}

TABLE 4: Litter sizes of outbred WZS minipigs at birth, $21 \mathrm{~d}$, and weaning in different birth frequencies.

\begin{tabular}{lccccc}
\hline \multirow{2}{*}{ Birth frequency } & Total & At birth & At 21 d & At weaning \\
\hline First birth $(n=40)$ & $6.35 \pm 1.53$ & $6.23 \pm 1.53$ & $5.63 \pm 1.92$ & $5.45 \pm 1.95$ & ANOVA, $P$ \\
Second birth $(n=26)$ & $7.08 \pm 1.75$ & $6.85 \pm 2.07$ & $6.57 \pm 1.99$ & $6.43 \pm 1.94$ & 0.1288 \\
Multibirth $(n=30)$ & $7.47 \pm 1.96$ & $6.87 \pm 1.78$ & $6.64 \pm 1.87$ & $6.12 \pm 1.79$ & 0.2963 \\
ANOVA, $P$ & 0.0281 & 0.2337 & 0.1602 & 0.4283 \\
\hline
\end{tabular}

Swine Breeds (GB 3038-82), Chinese national standards. Reproductive behavior parameters include male first penis protruding time, male first ejaculation time, female puberty, and female gestation. Litter performances include litter sizes, litter weights, and individual weights at birth, $21 \mathrm{~d}$, and weaning $(45 \mathrm{~d})$.

2.5. Haematology and Blood Biochemistry. Nineteen haematological indices were determined by automatic hematology analyzer (Sysmex XT-2000iv), and 12 blood biochemistry indices were determined by automatic biochemical analyzer (Hitachi 7020).

2.6. Microsatellite Analysis. Twenty-six commonly used microsatellite loci were employed to analyze the genetic diversity of the outbred WZS minipigs by multi-PCR as previous report [12]. The loci and grouping in multi-PCR were listed in Table 1. Samples of ears or blood from 44 randomly selected animals were used.

2.7. Organ Coefficients and Carcass Properties. The minipigs (females and castrated males) were slaughtered according to standard procedures. The internal organs were removed and weighed as described in rats [13]. After that, the organ coefficients were counted, which were relative (\% of body weight) organ weights. Then the carcass properties were determined according to Chinese Technical Regulation for Testing of Carcass Traits in Lean-Type Pigs (NY/T825-2004) [14].

2.8. Data Analysis. Data are expressed as means \pm SD. Student's $t$-tests were used to analyze between-group differences. Variances of different time points in the same group were analyzed by one-way ANOVA. A value of $P$ less than 0.05 was considered statistically significant. All analyses were done by using SAS software, version 8.01 (SAS Institute, Cary, North Carolina).

\section{Results and Discussion}

3.1. Physical Characteristics. Figure 1 shows the typical characteristics of outbred WZS minipigs. WZS minipigs have low body weight, slim body shape, and a small head with a long snout. Each trotter (foot) has four hoofed toes with the two larger central toes bearing most of the weight. The dental formula of adult pigs is the same as domestic pigs, giving a total of 44 teeth. The most common appearance of WZS minipigs is a black or brown body with white abdomen and legs and a white triangle on its forehead. Original WZS minipigs are normally active with sensitive response, while the temperament of outbred WZS minipigs tends to be gentle as domestic pigs. Detailed data on temperament and behaviour of outbred WZS minipigs will be evaluated and compared with original and inbred WZS minipigs in future studies.

\subsection{Growth Performance}

3.2.1. Body Weight. The minipigs were weighed routinely at a month interval up to 12 months and then at the interval of 6 months. All data are shown in Table 2. The body weights resemble Göttingen minipigs, the famous and widely used minipigs $[15,16]$. The mean body weights of birth, 2 months old, 6 months old, and 12 months old are as follows: $0.57 \pm$ $0.11 \mathrm{~kg}, 4.54 \pm 1.66 \mathrm{~kg}, 12.11 \pm 2.99 \mathrm{~kg}$, and $26.21 \pm 6.24 \mathrm{~kg}$. The mean body weight of 6 months old is higher than that of WZS minipigs bred in original region $(8.41 \pm 2.13 \mathrm{~kg})$ [17], but it is lower than that of WZS minipigs bred in Beijing, nonoriginal region $(13.43 \pm 3.27 \mathrm{~kg})$ [18]. It is also lower than other Chinese famous minipigs such as Guizhou minipigs [19] and Banna mini- and micropigs [19]. In Figure 2, as age increases, the body weights show a rapid increase at the first year (12 months) and then increase slightly. Body weight data were further analyzed by the following nonlinear theoretical models as described previously [16]: logistic, Gompertz, Bertalanffy, and Richards. Though all the $R^{2}$ of nonlinear theoretical models are above 0.99 , the Gompertz growth model is more suitable for our research for the maximum body weight drawing from Gompertz growth model is more practical (Figure 2). According to the Gompertz growth model, the maximum weight, inflection point of age, inflection point of body weight, and maximum daily increase of body weight are $45.82 \mathrm{~kg}, 230.11 \mathrm{~d}, 16.86 \mathrm{~kg}$, and $0.0883 \mathrm{~kg}$, respectively. 
TABLE 5: Litter weights and body weights of outbred WZS minipigs in different frequencies.

\begin{tabular}{lcccc}
\hline Birth frequency & Litter weight $(\mathrm{kg})$ & At birth & \multicolumn{2}{c}{ Individual weight $(\mathrm{kg})$} \\
At 21 d & $2.24 \pm 0.67$ & $3.35 \pm 1.23$ \\
\hline First birth $(n=40)$ & $3.54 \pm 1.07$ & $0.57 \pm 0.14$ & $2.30 \pm 0.81$ & $3.37 \pm 1.29$ \\
Second birth $(n=26)$ & $3.71 \pm 1.25$ & $0.56 \pm 0.13$ & $2.28 \pm 0.64$ & $3.18 \pm 0.92$ \\
Multibirth $(n=30)$ & $4.13 \pm 0.90$ & $0.56 \pm 0.12$ & 0.7119 & 0.3244 \\
ANOVA, $P$ & 0.7302 & 0.7856 & & At weaning \\
\hline
\end{tabular}

TABLE 6: Determination of haematological parameters.

\begin{tabular}{|c|c|c|c|c|}
\hline Parameters & Abbreviation & Unit & Male $(n=39)$ & Female $(n=45)$ \\
\hline White blood cells & WBC & $1 \times 10^{9} / \mathrm{L}$ & $17.47 \pm 4.50$ & $16.59 \pm 6.19$ \\
\hline Red blood cells & $\mathrm{RBC}$ & $1 \times 10^{12} / \mathrm{L}$ & $8.58 \pm 2.48$ & $8.87 \pm 1.25$ \\
\hline Haemoglobin & $\mathrm{HB}$ & $\mathrm{g} / \mathrm{L}$ & $155.37 \pm 38.90$ & $156.44 \pm 18.66$ \\
\hline Hematocrit & HCT & $\%$ & $51.76 \pm 12.70$ & $51.81 \pm 6.57$ \\
\hline Mean cell volume & $\mathrm{MCV}$ & $\mathrm{fL}$ & $66.10 \pm 5.84$ & $58.80 \pm 5.83$ \\
\hline Mean cell hemoglobin & $\mathrm{MCH}$ & $\mathrm{Pg}$ & $18.32 \pm 1.78$ & $17.76 \pm 1.62$ \\
\hline Mean cell hemoglobin concentration & $\mathrm{MCHC}$ & $\mathrm{g} / \mathrm{L}$ & $300.26 \pm 13.06$ & $302.44 \pm 11.74$ \\
\hline Total platelet count & PLT & $1 \times 10^{9} / \mathrm{L}$ & $308.47 \pm 121.70$ & $363.96 \pm 95.69$ \\
\hline Platelet distribution width & PDW & $\mathrm{fL}$ & $13.81 \pm 3.04$ & $14.48 \pm 1.71$ \\
\hline Platelet distribution width-SD & RDW-SD & $\mathrm{fL}$ & $42.63 \pm 3.77$ & $42.46 \pm 4.57$ \\
\hline Platelet distribution width-CV & RDW-CV & $\%$ & $21.65 \pm 3.07$ & $22.23 \pm 2.39$ \\
\hline Mean platelet volume & MPV & $\mathrm{fL}$ & $10.35 \pm 1.19$ & $10.90 \pm 0.78$ \\
\hline Platelet-large cell ratio & P-LCR & $\%$ & $31.31 \pm 8.94$ & $33.71 \pm 5.27$ \\
\hline Plateletcrit & PCT & $\%$ & $0.21 \pm 0.06$ & $0.21 \pm 0.05$ \\
\hline Neutrophils & NEUTRO & $1 \times 10^{9} / \mathrm{L}$ & $5.96 \pm 2.53$ & $6.96 \pm 2.68$ \\
\hline Lymphocytes & LYMPHO & $1 \times 10^{9} / \mathrm{L}$ & $10.20 \pm 4.39$ & $9.61 \pm 4.98$ \\
\hline Monocytes & MONO & $1 \times 10^{9} / \mathrm{L}$ & $0.60 \pm 0.29$ & $0.60 \pm 0.22$ \\
\hline Eosinophils & $\mathrm{EO}$ & $1 \times 10^{9} / \mathrm{L}$ & $0.47 \pm 0.23$ & $0.36 \pm 0.15^{*}$ \\
\hline Basophils & BASO & $1 \times 10^{9} / \mathrm{L}$ & $0.24 \pm 0.19$ & $0.21 \pm 0.10$ \\
\hline
\end{tabular}

Note: results of $t$-test and comparison between males and females. ${ }^{*} P<0.05$.

3.2.2. Body Measurement. Fifteen indices of body measurements were carried out monthly up to 12 months and results were shown in Table 2 . The mean values of body height, body length, chest depth, chest breadth, chest circumference, abdomen circumference, shank circumference, buttocks length, buttocks breadth, head length, forehead breadth, jaw width, caudal length, and caudal circumference of six-month-old WZS minipigs are as follows: $32.64 \pm$ $3.81 \mathrm{~cm}, 52.13 \pm 5.43 \mathrm{~cm}, 16.80 \pm 2.09 \mathrm{~cm}, 13.95 \pm 1.61 \mathrm{~cm}$, $50.64 \pm 5.77 \mathrm{~cm}, 58.30 \pm 5.88 \mathrm{~cm}, 8.51 \pm 0.74 \mathrm{~cm}, 18.77 \pm$ $2.29 \mathrm{~cm}, 11.95 \pm 1.31 \mathrm{~cm}, 17.75 \pm 1.47 \mathrm{~cm}, 7.93 \pm 0.54 \mathrm{~cm}, 9.74 \pm$ $0.90 \mathrm{~cm}, 14.90 \pm 2.40 \mathrm{~cm}$, and $5.10 \pm 0.68 \mathrm{~cm}$. These data are a little higher than the values of WZS minipigs bred in original region and lower than the values of WZS minipigs bred in Beijing. And they are also lower than Chinese Guizhou minipigs [19] and Banna mini- and micropigs [19]. The mean body measurements values of 12-month-old WZS minipigs are as follows: $42.96 \pm 3.37 \mathrm{~cm}, 67.38 \pm 6.35 \mathrm{~cm}, 22.94 \pm$ $2.82 \mathrm{~cm}, 17.59 \pm 2.74 \mathrm{~cm}, 67.49 \pm 7.74 \mathrm{~cm}, 74.69 \pm 9.19 \mathrm{~cm}, 10.63$ $\pm 0.78 \mathrm{~cm}, 24.75 \pm 2.28 \mathrm{~cm}, 15.86 \pm 1.64 \mathrm{~cm}, 23.19 \pm 1.58 \mathrm{~cm}$, $9.68 \pm 0.70 \mathrm{~cm}, 12.70 \pm 1.17 \mathrm{~cm}, 19.13 \pm 2.11 \mathrm{~cm}$, and $6.72 \pm$ $0.72 \mathrm{~cm}$.
The body measurements changing curves are the same as that of body weight showing rapid to slight increase. But the increases of body measurements in 1st month are significantly sharper than other months. Results show that WZS minipigs have the biological characteristics of small size and slow growing.

\subsection{Reproductive Performance}

3.3.1. Reproductive Behavior Parameters. The sexual mature time of males is earlier than that of females in WZS minipigs. For males, the first penis protruding time is $39.56 \pm 2.35 \mathrm{~d}$ $(n=45)$, and the first ejaculation time is $61.29 \pm 3.07 \mathrm{~d}(n=$ 36). For females, puberty, the age of females emerging first estrus, is $93.65 \pm 3.50 \mathrm{~d}$. Females in estrus will often assume the lordosis reflex, and the vulvar lips are swollen and red with a thin, mucous discharge. They also show some other signs of estrus including depressed appetite, restlessness, alertness, pacing, grunting, and chomping of the jaws. The period from the last end of estrus to this end, called estrus cycle, is $21.16 \pm 0.75 \mathrm{~d}$ for female WZS minipigs. And the 
TABLE 7: Determination of the haemal biochemical parameters.

\begin{tabular}{lcccc}
\hline Parameters & Abbreviation & Unit & Male $(n=35)$ & Female $(n=42)$ \\
\hline Alanine aminotransferase & ALT & $\mathrm{U} / \mathrm{L}$ & $88.33 \pm 24.27$ & $79.26 \pm 16.93$ \\
Aspartate aminotransferase & AST & $\mathrm{U} / \mathrm{L}$ & $63.00 \pm 26.03$ & $61.78 \pm 32.28$ \\
Alkaline phosphatase & ALP & $\mathrm{U} / \mathrm{L}$ & $239.07 \pm 135.90$ & $273.13 \pm 146.09$ \\
Total protein & $\mathrm{TP}$ & $\mathrm{g} / \mathrm{L}$ & $85.25 \pm 5.29$ & $82.87 \pm 10.79$ \\
Albumin & $\mathrm{ALB}$ & $\mathrm{g} / \mathrm{L}$ & $35.41 \pm 3.24$ & $32.89 \pm 6.16$ \\
Globulin & $\mathrm{GLB}$ & $\mathrm{g} / \mathrm{L}$ & $49.84 \pm 5.81$ & $49.99 \pm 8.67$ \\
Blood urea nitrogen & $\mathrm{BUN}$ & $\mathrm{mmol} / \mathrm{L}$ & $6.47 \pm 5.48$ & $4.15 \pm 1.49^{*}$ \\
Creatinine & $\mathrm{CREA}$ & $\mathrm{mmol} / \mathrm{L}$ & $148.86 \pm 62.16$ & $127.91 \pm 37.18$ \\
Glucose & GLU & $\mathrm{mmol} / \mathrm{L}$ & $1.93 \pm 0.51 \pm 2.95$ & $5.65 \pm 2.02$ \\
Cholesterol & $\mathrm{CHOL}$ & $\mu \mathrm{mol} / \mathrm{L}$ & $0.50 \pm 0.37$ & $2.69 \pm 0.58^{*}$ \\
Total bilirubin & TBILI & $\mathrm{mmol} / \mathrm{L}$ & $0.45 \pm 0.19$ & $0.43 \pm 0.69$ \\
Triglycerides & TG & & & $0.59 \pm 0.24^{*}$ \\
\hline
\end{tabular}

Note: results of $t$-test and comparison between males and females. ${ }^{*} P<0.05$.

behavioral estrus sustains $4.18 \pm 0.31 \mathrm{~d}$. After fertilization, females will experience $113.0 \pm 2.33$ d gestation till parturition. Table 3 describes the main reproductive behavior parameters of female WZS minipigs.

3.3.2. Litter Performance. The overall litter characteristics of the present study are given in Tables 4 and 5, and the differences in litter performances are also shown in them. In Table 4, the effects on litter sizes caused by birth frequencies are illustrated. As birth frequencies increase, the total litter sizes at birth are increasing; however, the survival numbers at birth, $21 \mathrm{~d}$, and weaning (about $45 \mathrm{~d}$ ) show no differences between each other. The mortality observed is comparable to values reported by others, showing that the larger the litter size the greater the mortality. The effects of birth frequencies on litter weights and individual weights, analyzed by the analysis of variance (ANOVA), are shown in Table 5. The litter weights show a small positive correlation with higher birth frequencies $(P>0.05)$, while these data provide no positive or negative correlations between birth frequencies and the individual weights at birth, $21 \mathrm{~d}$, and weaning.

3.4. Hematology and Blood Biochemistry. Hematology and blood biochemistry indices are important to animals for evaluation of their homeostasis and disease diagnosis. Tables 6 and 7 present the background data of hematology and blood biochemistry for outbred WZS minipigs aged from 2 to 12 months and this range of ages represents the main range encountered in toxicological and biological studies $[2,3,20]$. In 19 haematological and 12 blood biochemical parameters, only EO, BUN, CHOL, and TG show significant differences between male and female WZS minipigs. The main differences of haematological parameters between closed colony and inbred strain [21] focus on indices of hemoglobin and blood platelet, and there were 6 different indices of biochemical parameters.

3.5. Microsatellite Analysis. Twenty-six commonly used microsatellite loci were employed to analyze the genetic diversity of the outbred WZS minipigs by multi-PCR. Results of 44 randomly selected animals showed that the mean allelic numbers per locus were 8.37 , the mean polymorphism information content (PIC) was 0.7069, and the mean heterozygosity $(\mathrm{H})$ was 0.5478 . The mean allelic numbers per locus, mean PIC, and mean $\mathrm{H}$ were significantly higher than those of inbred WZS minipigs reported elsewhere [12], which were $6.92,0.6042$, and 0.4478 , respectively. Yao et al. had employed twenty-seven microsatellite markers recommended by the Food and Agriculture Organization (FAO) and the International Society for Animal Genetics (ISAG) to analyze the genetic diversities of WZS minipigs bred in original region, Hainan, China [22]. Their results are similar to our results. These data present that the outbred WZS minipigs are genetically stabilized breed with high heterozygosity and maintain the original characteristics.

3.6. Organ Coefficients. Seventy-four healthy WZS minipigs (43 males and 31 females) aged from 5 to 20 months were chosen to determine 6 organs weights and organ coefficients. Data are listed in Table 8. Student's $t$-test is employed to analyze the differences of organ weights and organ coefficients between males and females of the same age range. Only few organ weights of different aged animals show significant difference between males and females $(P<0.05)$; they are lung weight of animals aged 5-9 months and kidney weight of animals aged 10-15 months, but there was no significant difference for the organ coefficients $(P>0.05)$. Furthermore, the effects of age factor on organ weights and organ coefficients were analyzed by ANOVA. Results of ANOVA showed that organ weights increased significantly in accordance with the growths and increases of body weights $(P<0.0001)$; the organ coefficients of heart, liver, lung, and stomach decreased significantly with the growth of animals $(P<0.0001)$, but the decreases of spleen and kidney coefficients were not significant $(P>0.05)$.

3.7. Carcass Properties. Sun and Lu [23] had reported some pork characteristics of WZS minipigs based on 3 young 


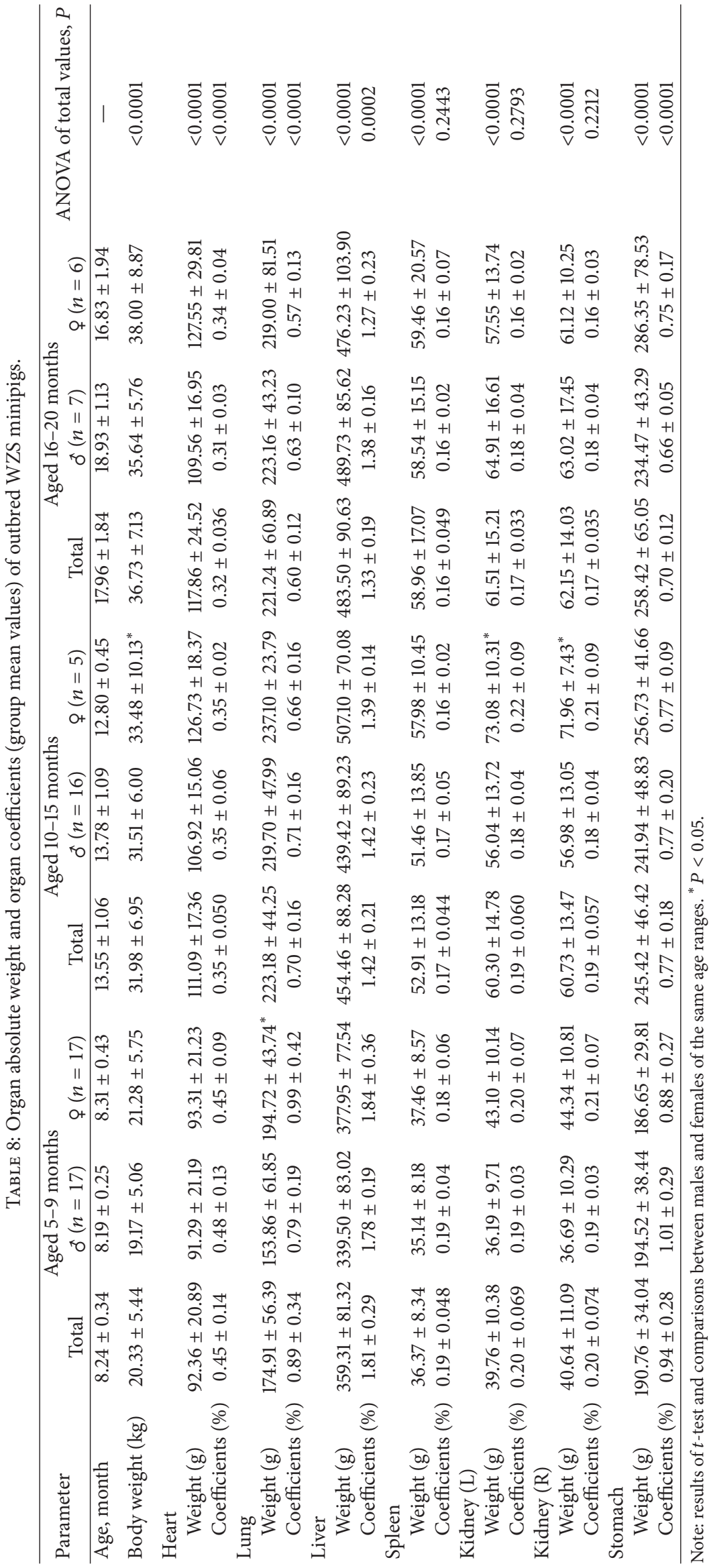


TABLE 9: Determination of carcass properties in outbred WZS minipigs.

\begin{tabular}{|c|c|c|c|}
\hline \multirow{2}{*}{ Item } & \multicolumn{3}{|c|}{ Means } \\
\hline & Total $(n=11)$ & Male $(n=5)$ & Female $(n=6)$ \\
\hline Body weight (kg) & $24.55 \pm 7.28$ & $22.92 \pm 10.21$ & $25.92 \pm 4.20$ \\
\hline Slaughter weight (kg) & $16.16 \pm 4.87$ & $14.89 \pm 6.65$ & $17.23 \pm 3.02$ \\
\hline Blood weight (kg) & $1.01 \pm 0.17$ & $0.99 \pm 0.09$ & $1.03 \pm 0.21$ \\
\hline Head weight (kg) & $2.97 \pm 0.73$ & $2.44 \pm 0.82$ & $3.33 \pm 0.41$ \\
\hline Forepaw weight (kg) & $0.31 \pm 0.09$ & $0.29 \pm 0.14$ & $0.33 \pm 0.07$ \\
\hline Rear foot weight (kg) & $0.38 \pm 0.11$ & $0.33 \pm 0.13$ & $0.43 \pm 0.08$ \\
\hline Suet (including kidney) (kg) & $0.31 \pm 0.03$ & $0.30 \pm 0.02$ & $0.31 \pm 0.04$ \\
\hline Lean meat weight (kg) & $8.57 \pm 2.37$ & $6.97 \pm 2.70$ & $9.84 \pm 1.06$ \\
\hline Fat weight (kg) & $2.50 \pm 1.72$ & $2.64 \pm 2.55$ & $2.39 \pm 1.01$ \\
\hline Bone weight (kg) & $1.95 \pm 0.54$ & $1.57 \pm 0.60$ & $2.25 \pm 1.01$ \\
\hline Skin weight (kg) & $2.22 \pm 0.79$ & $1.94 \pm 1.16$ & $2.45 \pm 0.34$ \\
\hline Skin thickness (mm) & $3.64 \pm 0.92$ & $3.40 \pm 1.14$ & $3.83 \pm 0.75$ \\
\hline Back fat thickness (mm) & $11.70 \pm 6.05$ & $11.47 \pm 6.76$ & $11.90 \pm 4.97$ \\
\hline Carcass length $(\mathrm{cm})$ & $47.30 \pm 4.72$ & $43.50 \pm 3.11$ & $49.83 \pm 3.87$ \\
\hline Eye muscle area $\left(\mathrm{cm}^{2}\right)$ & $15.55 \pm 2.81$ & $14.66 \pm 2.66$ & $16.29 \pm 1.87$ \\
\hline Dressing percentage (\%) & $66.03 \pm 2.52$ & $65.55 \pm 3.67$ & $66.35 \pm 1.95$ \\
\hline Lean meat percentage (\%) & $57.11 \pm 4.86$ & $55.61 \pm 6.57$ & $58.31 \pm 3.30$ \\
\hline Fat meat percentage (\%) & $15.31 \pm 6.35$ & $17.17 \pm 8.46$ & $13.82 \pm 4.56$ \\
\hline Bone percentage (\%) & $12.64 \pm 2.58$ & $12.63 \pm 3.87$ & $12.64 \pm 1.44$ \\
\hline Skin percentage (\%) & $14.36 \pm 1.45$ & $14.19 \pm 1.97$ & $14.49 \pm 1.11$ \\
\hline
\end{tabular}

Note: no significant differences were found between males and females by $t$-test.

TABLE 10: Results of sensory character $(n=11)$.

\begin{tabular}{llcccrr}
\hline \multirow{2}{*}{ Item } & \multicolumn{2}{c}{ Meat color $^{\mathrm{a}}$} & \multicolumn{2}{c}{ Elasticity $^{\mathrm{b}}$} & \multicolumn{2}{c}{ Marbling $^{\mathrm{c}}$} \\
& Fresh meat & Cool meat & Fresh meat & Cool meat & Fresh meat & Cool meat \\
\hline Result & $2.57 \pm 0.62$ & $2.76 \pm 1.41$ & Good & Good & - & $4.35 \pm 0.19$ \\
\hline
\end{tabular}

Note: ${ }^{a}$ meat sensory character was evaluated as described previously [11]. Meat color categories: 1, pale-purplish gray; 2 , grayish pink; 3, reddish pink; 4, purplish red; 5, dark, purplish red. ${ }^{b}$ Meat elasticity was classified to three levels: good, normal, and poor by hand pressing. ${ }^{\mathrm{c}}$ For meat marbling, score of 1 is devoid of fat and 10 has abundant marbling.

and 3 adult minipigs [23]. In this study, we extensively determined the carcass properties of 11 adult WZS minipigs aged from 6 to 10 months. All detected carcass traits are shown in Tables 9 and 10. According to Table 9, there are no significant differences between males and females for all carcass properties. When compared to the same age range domestic pigs [24], all the traits of WZS minipigs are significantly lower, indicating a lean-type pig. For males, the comparisons between WZS minipigs and Tibet minipigs in China [24] show that skin thickness, back fat thickness, bone percentage, and skin percentage of WZS minipigs are higher than those of Tiber minipigs. Besides the above traits, the eye muscle area of WZS minipigs is also higher than that of Tibet minipigs for females. Results of sensory characters in Table 10 demonstrate that WZS minipigs are of perfect meat color, meat elasticity, and less marbling.

\section{Conclusion}

In conclusion, we report the detailed biological characteristics of outbred WZS minipigs cultivated for more than ten years. Series of background parameters have been detected out and proved to be stable in outbred WZS minipigs. Reproductive performances show that sexual maturity of sow is earlier than domestic pigs. Growth performances demonstrate that WZS minipigs have downsizing body shape and low body weight. Microsatellite analysis reveals the high heterozygosity of WZS minipigs. Organ coefficients, hematology, and blood biochemistry indices are stable. These results indicate that outbred WZS minipigs are suitable laboratory animals and could be widely used in comparative medicine and bioresearches in future.

\section{Conflict of Interests}

The authors declare that there is no conflict of interests regarding the publication of this paper.

\section{Authors' Contribution}

Fangui Min and Jinchun Pan made equal contributions to this study. 


\section{Acknowledgments}

This work was supported by Grants nos. 2010B0605000180 and 2011B020305002 of Guangdong Provincial Science and Technology Project and Grant no. 11A66100095 of Guangzhou Science and Technology Project.

\section{References}

[1] N. A. Montiero-Riviere and J. Riviere, "The pig as a model for cutaneous pharmacology and toxicology research," in Advances in Swine in Biomedical Research, L. B. Schook and M. E. Tumbleson, Eds., vol. 2, pp. 425-458, Plenum Press, New York, NY, USA, 1996.

[2] J. Mortensen, P. Brinck, and J. Lichtenberg, "The minipig in dermal toxicology-a literature review," Scandinavian Journal of Laboratory Animal Science, vol. 25, no. 1, pp. 77-83, 1998.

[3] J. W. van der Laan, J. Brightwell, P. McAnulty, J. Ratky, and C. Stark, "Regulatory acceptability of the minipig in the development of pharmaceuticals, chemicals and other products," Journal of Pharmacological and Toxicological Methods, vol. 62, no. 3, pp. 184-195, 2010.

[4] F. Köhn, "History and development of miniature, micro-and minipigs," in The Minipigs in Biomedical Research, P. A. McAnulty, A. D. Dayan, N. C. Ganderup, and K. L. Hastings, Eds., pp. 3-6, CC Press, 2011.

[5] H. T. Shang and H. Wei, "Preliminary analysis of Chinese miniature pig strains and resources," Acta Laboratorium Animalis Scientia Sinica, vol. 15, no. 1, pp. 70-75, 2007.

[6] X. L. Wang, F. G. Min, J. C. Pan et al., "Selection and breeding of experimental Wuzhishan minipigs," Laboratory Animal and Comparative Medicine, vol. 31, no. 5, pp. 345-348, 2011.

[7] Q. Huang, H. Xu, Z. Yu, P. Gao, and S. Liu, "Inbred Chinese Wuzhishan (WZS) minipig model for soybean glycinin and $\beta$ conglycinin allergy," Journal of Agricultural and Food Chemistry, vol. 58, no. 8, pp. 5194-5198, 2010.

[8] D. H. Yang, X. L. Ren, F. Xu et al., "Absorptive constituents and their metabolites in drug-containing urine samples from Wuzhishan miniature pigs orally administered with Buyang Huanwu decoction," Journal of Natural Medicines, vol. 68, no. 1, pp. 11-21, 2014.

[9] Q. F. Zhang, S. T. Feng, Y. L. Mao, Y. Zhang, and Q. D. Wang, "The analysis and fitting on growth curves of Chinese WZS minipig," Sichuan College of Animal Science \& Veterinary Medicine, vol. 33, pp. 28-32, 2006.

[10] S. T. Feng, "The experimentally cultivation and application of Chinese minipigs," Laboratory Animal Science, vol. 24, no. 6, pp. 111-118, 2007.

[11] NPB (National pork board), Pork Quality Standards, National Pork Board, Des Moines, Iowa, USA, 1999.

[12] W. Yuan, J. Wang, X. M. Liu, F. G. Min, J. C. Pan, and X. L. Wang, "Genetic analysis of microsatellite DNA Loci in inbred Wuzhishan minipig," Laboratory Animal Comparative Medicine, vol. 32, no. 4, pp. 329-333, 2012.

[13] E. Gur and T. Waner, "The variability of organ weight background data in rats," Laboratory Animals, vol. 27, no. 1, pp. 6572, 1993.

[14] MOA (Ministry of Agriculture of the People's Republic of China), Chinese Technical Regulation for Testing of Carcass Traits in Lean-Type Pigs, Chinese National Standard Bureau Press, Beijing, China, 2004.
[15] F. Köhn, A. R. Sharifi, Š. Malovrh, and H. Simianer, "Estimation of genetic parameters for body weight of the Goettingen minipig with random regression models," Journal of Animal Science, vol. 85, no. 10, pp. 2423-2428, 2007.

[16] F. Köhn, A. R. Sharifi, and H. Simianer, "Modeling the growth of the Goettingen minipig," Journal of Animal Science, vol. 85, no. 1, pp. 84-92, 2007.

[17] F. Wang, L. M. Wei, X. L. Zheng, and R. P. Sun, "Growth and development performance of Wuzhishan minipigs bred in Hainan," J Swine Ind Sci, no. 5, pp. 108-109, 2009.

[18] P. F. Gao, Q. F. Zhang, and Q. D. Wang, "A study on the growth curve analysis and fitting of inbred Wuzhishan Minipig (WZSP)," Chinese Journal of Animal Husbandry \& Veterinary Medicine, vol. 9, pp. 31-32, 2005.

[19] P. L. Zheng, Z. G. Zhang, X. H. Chen, and Y. R. Tu, Wuzhishan Minipigs, Guizhou Minipigs, Diannan Minipigs Chinese Indigenous Pig Breeds, Shanghai Science and Technology Press, 1986.

[20] R. Forster, P. Ancian, M. Fredholm, H. Simianer, and B. Whitelaw, "The minipig as a platform for new technologies in toxicology," Journal of Pharmacological and Toxicological Methods, vol. 62, no. 3, pp. 227-235, 2010.

[21] S. L. Yang, H. Y. Ren, H. Wang et al., "Investigation of the blood biochemistry parameters of three Chinese indigenous laboratory miniature pig breeds," China Animal Husbandry \& Veterinary Medicine, vol. 34, no. 4, pp. 75-78, 2007.

[22] S. K. Yao, Q. Zhang, F. Z. Sun, and P. Q. Liu, "Genetic diversity of seven miniature pig breeds (strains) analyzed by using microsatellite markers," Hereditas, vol. 28, no. 4, pp. 407-412, 2006.

[23] J. S. Sun and F. Lu, "Study on pork characteristics of Chinese Wuzhishan mini-pig," Pakistan Journal of Nutrition, vol. 1, no. 4, pp. 169-173, 2002.

[24] Y. Z. Chamba, H. Zhang, S. L. Ji, Y. Ling, Q. Wang, and D. Zhan, "Measurement and analysis of slaughter performance and meat quality of Tibet minipig," Chinese Journal of Animal Science, vol. 44, no. 21, pp. 10-11, 2008. 

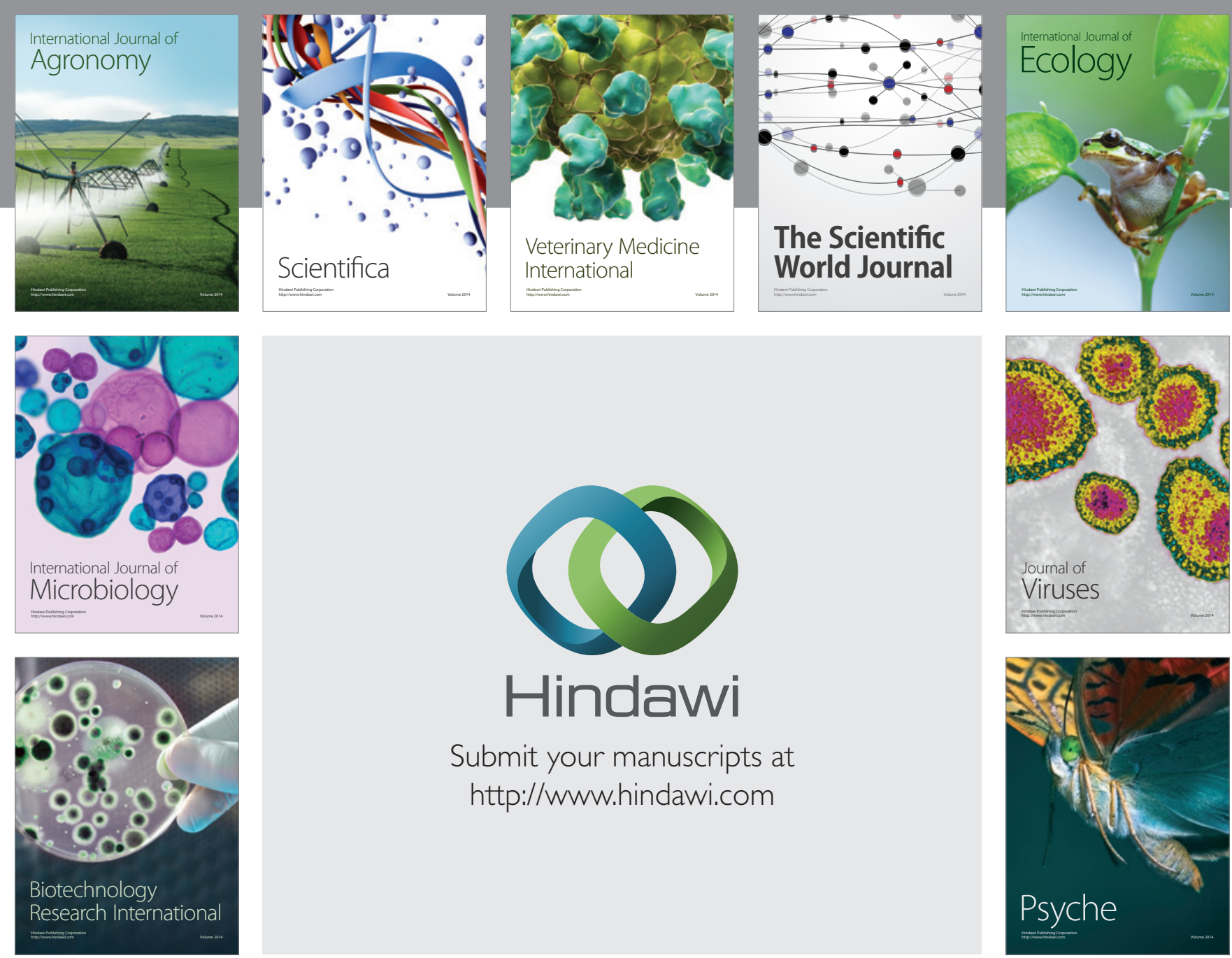

Submit your manuscripts at http://www.hindawi.com
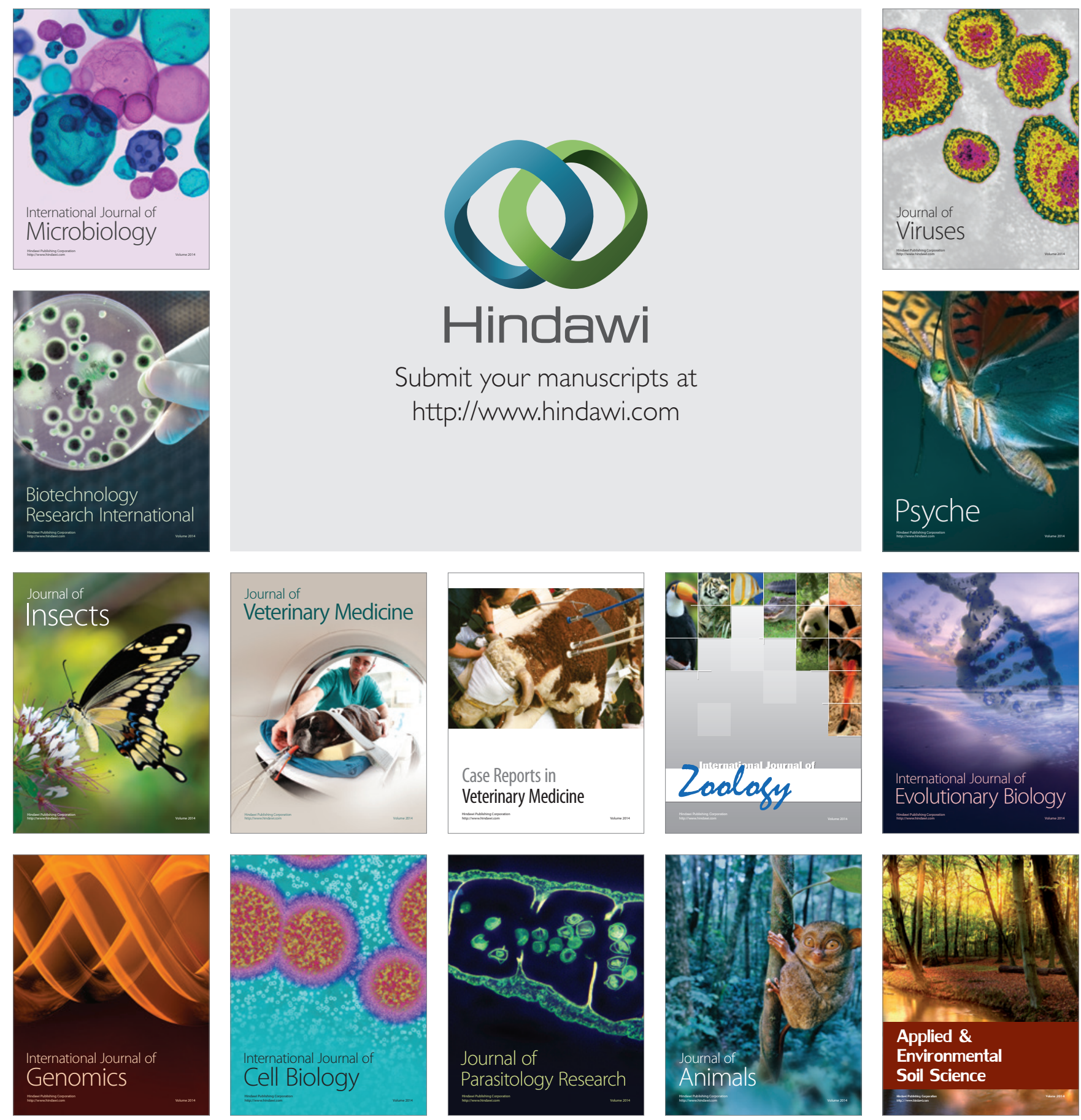